\title{
Characterization of Temperature and Productive Torque for 1601 Frame Squirrel Cage Induction Motor
}

\author{
Sudha.B, Anusha Vadde, Krishnan Manickavasagam and Govind R Kadambi
}

Department of Electrical Engineering, Ramaiah University of Applied Sciences, INDIA.

Corresponding Author: sudha.ee.et@msruas.ac.in

\begin{abstract}
Induction motor usage is increasing drastically due to new entrant of electric vehicle, traction and propulsion systems at present. Temperature of electric motors are significantly affect its parameters. Since, resistances variation of stator and rotor winding are depend on temperature, the torque speed characteristics also affects in the induction motors. In this paper, a innovative approach is proposed to arrive the relation of temperature on torque. Thermal analysis of $160 \mathrm{~L}$-frame induction motors is carried out using Finite Element Method (FEM) under various load to obtain temperature. The mathematical relationship between temperature and torque is arrived using curve fitting technique. The expression arrived in this method is used to predict the torque for a given temperature of SCIM.

Keywords: Finite element analysis (FEA); Squirrel cage induction motor (SCIM); Totally enclosed fan cooled (TEFC); Temperature; Torque.

\section{INTRODUCTION}

Induction motors are the main workhorse of all industry and they are mainly used to operate at constant speed. The induction motors often used due to its low cost, robust construction, reliable and high-efficiency. The life of induction motor depends on various factors such as heavy-duty, load, duty cycle, environmental stress, improper installation, temperature dissipation and manufacture imperfections. The temperature of the motor is causing main problem and creating for malfunction of an induction motor. Induction motors are widely used in various applications such as electric vehicles, hybrid electric vehicles, chillers, land and ship, fans, mills, extruders, de-brakers, compressors, shredders, crushers, blowers, cranes, , (Gao, Z. 2006). The failure ratio of induction motor is 3-5 percent per annum and for big industries the failure rate is 12 percent per annum (Kylander, G.1995). According to study made in (Kylander, G.1995), most of this failure occurs due to incessant heating of various parts of the motor while in operation most. Feature study of thermal effects has shown that most of the motor failures are related either indirectly or directly to incessant heating of various parts of motor during machine operation (Kylander, G.1995). The overheating of motor causes stator insulation degradation and deformation of rotor resistance value. The chemical process of humiliation of stator insulation is governed by Arrhenius equation in (Boglietti et al., 2009).Obtaining an accurate value for the thermal limit of rotor is quite impractical. Absence of rotor insulation in conductors allowed the rotor to operate in higher temperature than stator (Bai et al., 2010). In electric vehicle and traction applications, the limit of temperature in electrical, magnetic and insulation is deciding the continuous operation. Beyond the limit, loss of dielectric property in insulating material, deterioration of bearing lubricants and mechanical distortion may occur due to temperature rise (Jebaseeli. 2015).
\end{abstract}


Different possibilities of modelling for estimation of thermal robustness of a traction motor is investigated in (Mezani et al, 2005 \& Staton et al, 2005).Finite-element analysis (FEA) is used commonly for electromagnetic problems (Boglietti et al, 2005). The thermal analysis of the induction motor in different conditions given in (Yuangjiang, 2000. Boglietti et al, 2008. Cezário et al, 2005. Dutta et al, 2013 \& Gao et al, 2005) only can able to solve conduction heat transfer accurately. The method of motor windings thermal analysis based on circuit model is characterized in (Mynarek et al, 2011).

Two methods of motor temperature-estimation techniques are proposed in (Popova, 2011). First type is using a thermal model to estimate inner temperatures. Second type uses the winding resistances and temperatures relationships to estimate the stator and rotor winding temperatures.

In this research, an attempt is made to find the temperature limit for obtaining operating range of useful torque. The main scope of the research is as following:

- To determine lower limit of temperature: below which torque developed by an induction motor is unproductive torque

- To determine upper limit of temperature: above which torque developed by an induction motor can bedetermined

- To obtain generalized equation of a given frame to find useful torque

\section{DESCRIPTION OF THE SYSTEM}

Computation of temperature includes heat transfer in both conduction and convection in all parts of the motor. The work flow as given in Figure 1.

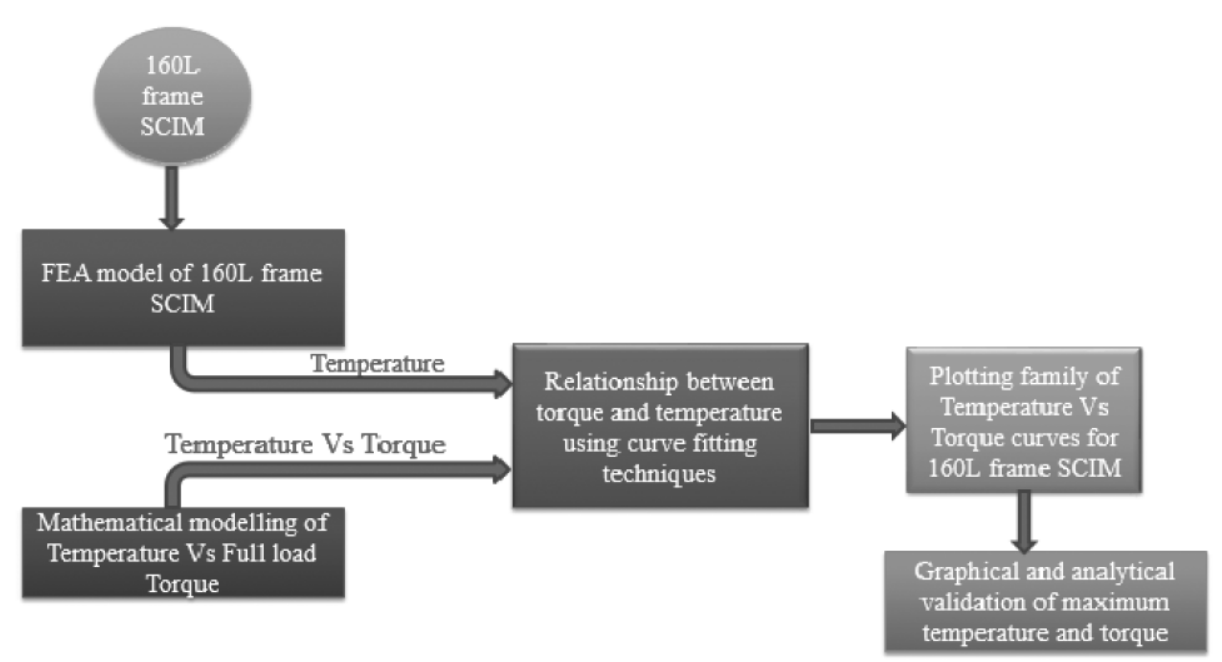

Figure 1. Work flow representation

The computation is performed using FEA for $160 \mathrm{~L}$-frame. The torque is arrived based on the temperature obtained from FEA. The computational procedure is repeated for $11 \mathrm{~kW}, 15 \mathrm{~kW}$ and $18.5 \mathrm{~kW}$ SCIM of $160 \mathrm{~L}$-frame. The work flow is explained in detail in the following sections. 


\section{FEA MODEL OF 160L-FRAME SCIM}

The procedure involved in prediction of temperature for $11 \mathrm{~kW}, 15 \mathrm{~kW}$ and $18.5 \mathrm{~kW}$ SCIM, $160 \mathrm{~L}-$ frame of motor as follows:

1. Arrive the specifications of TEFC type SCIM

2. Calculate input heat sources in $\mathrm{W} / \mathrm{m} 3$ from given motor specifications for no load, $1 / 2,3 / 4$ th load and full load

3. Develop FEA model using the heat sources

4. Obtain temperature rise for different parts of the motor

\section{SPECIFICATION OF TEFC INDUCTION MOTOR}

Heat sources are computed from the specifications of the 3-phase, $15 \mathrm{~kW}$, TEFC, SCIM as given in Table 1.The related formulae used are given in Appendix. The formula used for computation is the same for all ratings of SCIM.

\section{CALCULATION OF HEAT SOURCES}

Heat sources are calculated in terms of the power losses per volume for $15 \mathrm{~kW}$ SCIM. The losses, volume and heat source are given in Table 2 which are the inputs of FEA. Similar way the heat sources are calculated for $11 \mathrm{~kW}$ and $18.5 \mathrm{~kW}$.

Table 1. Specifications of the $15 \mathrm{~kW}$ type induction motor

\begin{tabular}{|c|c|}
\hline Type & M2BAX160MLB4 (IE1) \\
\hline Voltage & V 415 \\
\hline Rated current & A 28.18 \\
\hline No load current & A 11.72 \\
\hline Power & $\mathrm{kW} 15$ \\
\hline Pole & no 4 \\
\hline Rated speed & rpm 1461.8 \\
\hline No load speed & rpm 1498 \\
\hline Efficiency & $90 \%$ \\
\hline Power factor & 0.822 \\
\hline Ambient temperature & $\mathrm{C}^{\circ} 25$ \\
\hline Stator temperature rise & $\mathrm{C}^{\circ} 70$ \\
\hline Temperature tolerance class & B \\
\hline Insulation class & $\mathrm{F}$ \\
\hline Stator resistance per phase & 0.2746 \\
\hline
\end{tabular}


Table 2. Calculation of heat sources for $15 \mathrm{~kW}$ SCIM

\begin{tabular}{|c|c|c|}
\hline Motor Components & $\begin{array}{c}\text { Calculation of } \\
\text { losses }(\mathbf{W})\end{array}$ & $\begin{array}{c}\text { Heat Sources } \\
(\mathbf{W} / \mathbf{m} 3)\end{array}$ \\
\hline Stator core & 247.14 & 56,795 \\
\hline Rotor core & 204.2 & $71,148.09$ \\
\hline Stator windings & 734.2 & $284,205.77$ \\
\hline Rotor bar & 5.43 & $10,053.69$ \\
\hline Shaft & 83.4 & $79,061.13$ \\
\hline Short circuit ring & 203.37 & $342,431.38$ \\
\hline
\end{tabular}

\section{PREDETERMINATION OF TEMPERATURE RISE USING FEA}

In order to examine and analyze the temperature rise of each part of the motor, FEA is performed on the mesh model of $15 \mathrm{~kW}$ SCIM. Temperature contour plots of the outer frame, shaft, stator windings and bearing DE at rated load condition are represented in Figure 2, which gives the prediction of the mean temperature values under steady state condition for the rated load at $298 \mathrm{~K}$ ambient temperature. From the temperature contour, it can be observed that the temperature at the axial center of each part of the motor is high compared to its driving and non-driving end. This can be observed from the colour of contour and ascending order of observed temperature as shown in figure 2. Thermal analysis is carried out at various loads under the steady-state condition of $298 \mathrm{~K}$ ambient temperature. The graph shows that temperature rise of various parts of the motor with respect to motor casing temperature at different loads in Kelvin ' $\mathrm{K}$ '. The stator winding temperature rise is high with respect to motor casing temperature rise. By knowing the casing temperature rise of the motor, the temperature distribution outside of the motor may cause effect to the environment particularly in Electric Vehicles.

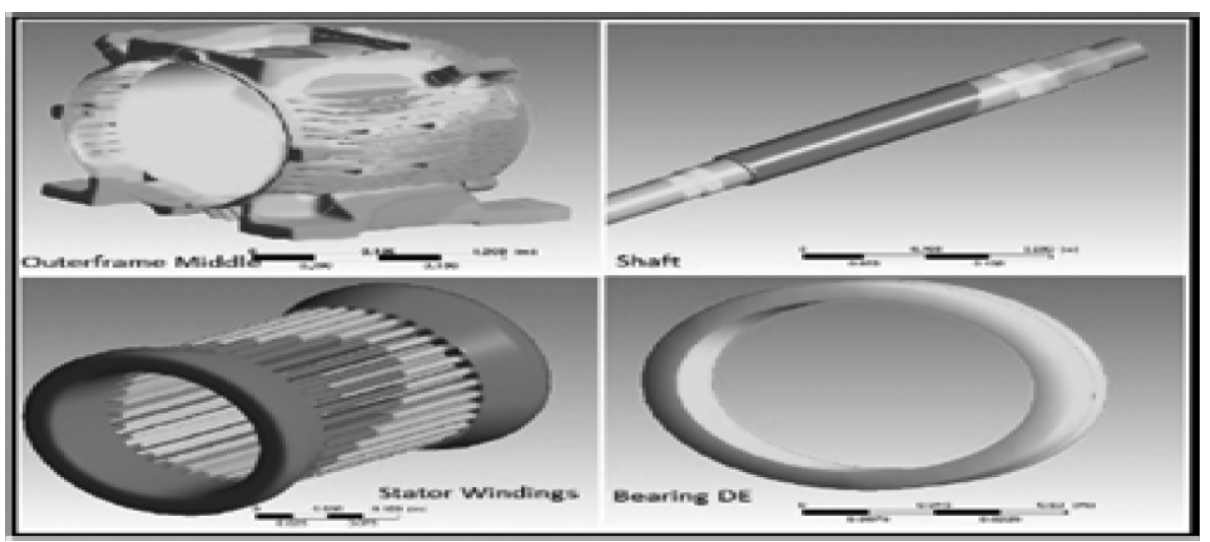

Figure 2. Distribution of heat in (a)Outer frame (b)Shaft(c)Stator windings(d)Bearing DE 


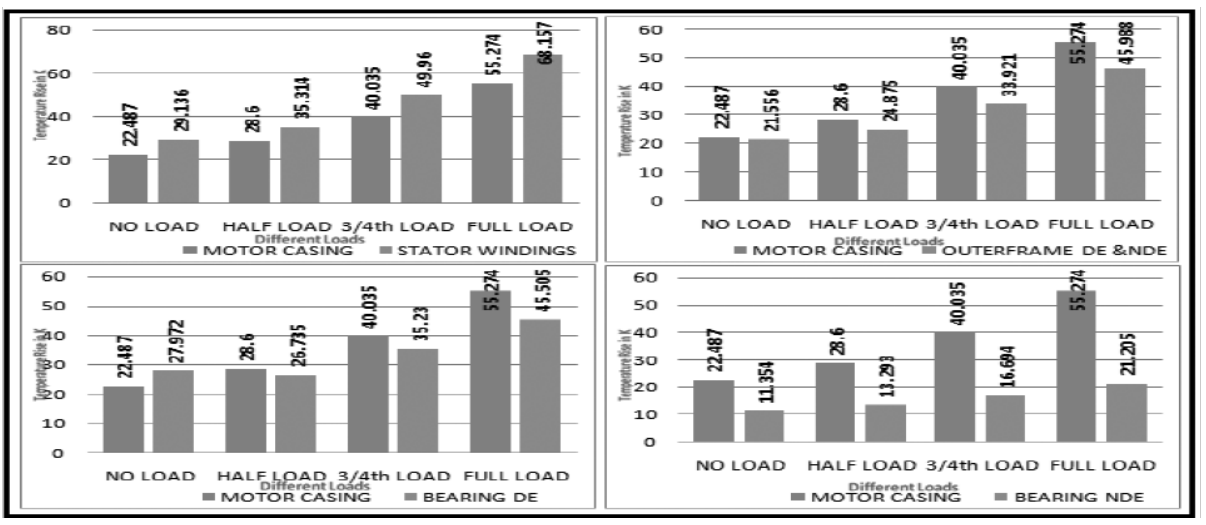

Figure 3. Prediction of temperature rise in different parts of motor at ambient temperature of $298 \mathrm{~K}$

\section{MATHEMATICAL MODELLING OF TORQUE AND TEMPERATURE}

A mathematical equation is arrived from existing equations for determining the relationship between temperature rise and torque.

By considering torque ' $\mathrm{T}$ ' of the motor

$$
T=\frac{3}{2 \pi N s} X \frac{S_{2}^{2} R_{2}}{R_{2}^{2}+\left(S_{2}^{2}\right)}
$$

Where ' $\mathrm{T}$ ' is Torque

$\mathrm{E}_{2}$ is rotor voltage or rated voltage, $\mathrm{X}_{2}$ is standstill reactance of rotor

$\mathrm{S}$ is slip (it varies for different loads)

$R_{2}$ is rotor resistance

By eliminating constants,

$$
\text { Torque } \alpha \frac{\mathbf{s} \mathbf{R}_{2}}{\mathbf{R}_{2}^{2}+\left(\mathbf{s}^{2} \mathbf{X}_{2}^{2}\right)}
$$

By replacing $R_{2}$ in terms of temperature rise

$$
R_{2}^{\prime}=R_{2}(1+\alpha \Delta t)
$$

Where, $\Delta \mathrm{t}=\mathrm{t}_{2}-\mathrm{t}_{1}$

$\mathrm{t} 2$ is operating temperature of motor and $\mathrm{t} 1$ is ambient temperature in ${ }^{\circ} \mathrm{C}$

Substituting equation (3) in equation (2),

$$
\text { Torque } \alpha \frac{s\left[R_{2}(1+\alpha \Delta t)\right]}{\left[R_{2}(1+\alpha \Delta t)\right]^{2}+\left(s X_{2}\right)^{2}}
$$


By simplifying,

$$
\begin{aligned}
& \text { Torque } \alpha \frac{s R_{2}(\infty \Delta t)}{\left[R_{2}(\infty \Delta t)\right]^{2}+\left(s X_{2}\right)^{2}} \\
& \text { Torque } \alpha \frac{\frac{R_{2}}{S}(\infty \Delta t)}{\left[\frac{R_{2}}{s}(\infty \Delta t)\right]^{2}+\left(\frac{X_{2}}{R_{2}}\right)^{2}} \\
& \text { Torque } \alpha \frac{s}{R_{2} \infty \Delta t}
\end{aligned}
$$

The relationship between torque and temperature rise is arrived.

\section{MATHEMATICAL FUNCTION OF TORQUE VERSUS TEMPERATURE RISE}

Mathematical equation (1) gives the relation of torque and temperature rise. From the equation (6), it can be observed that the effect of temperature rise only dependent on rotor temperature. Temperature from FEA substituted in equation (1) in terms of resistance to get torque which are displayed in Table 3 . The values of slip is calculated based on speed and slip relation as given in Appendix , equation (13). Rotor resistance and reactance parameters are calculated as given Appendix equation number (19) \& (22). Graph between rotor temperature rise versus torque is plotted in figure 4 . Figure 4 shows variation of torque with respect to rotor temperature rise obtained from FEA. Since under no load, the temperature rise is approximately equal to ambient temperature only. To observe the complete performance of $15 \mathrm{~kW}$ SCIM from lower temperature rise to maximum temperature rise a suitable relation should be identified.

Table 3. Rotor temperature rise and torque for $15 \mathrm{~kW} \mathrm{SCIM}$

\begin{tabular}{|c|c|c|c|}
\hline Loads & Slip & Rotor temperature rise $\left({ }^{\circ} \mathbf{C}\right)$ & Torque $(\mathbf{N}-\mathbf{m})$ \\
\hline Half load & 0.01273 & 34.8 & 24.0845 \\
\hline 3/4th load & 0.01909 & 48.45 & 34.3569 \\
\hline Full load & 0.02546 & 66.413 & 43.043 \\
\hline
\end{tabular}




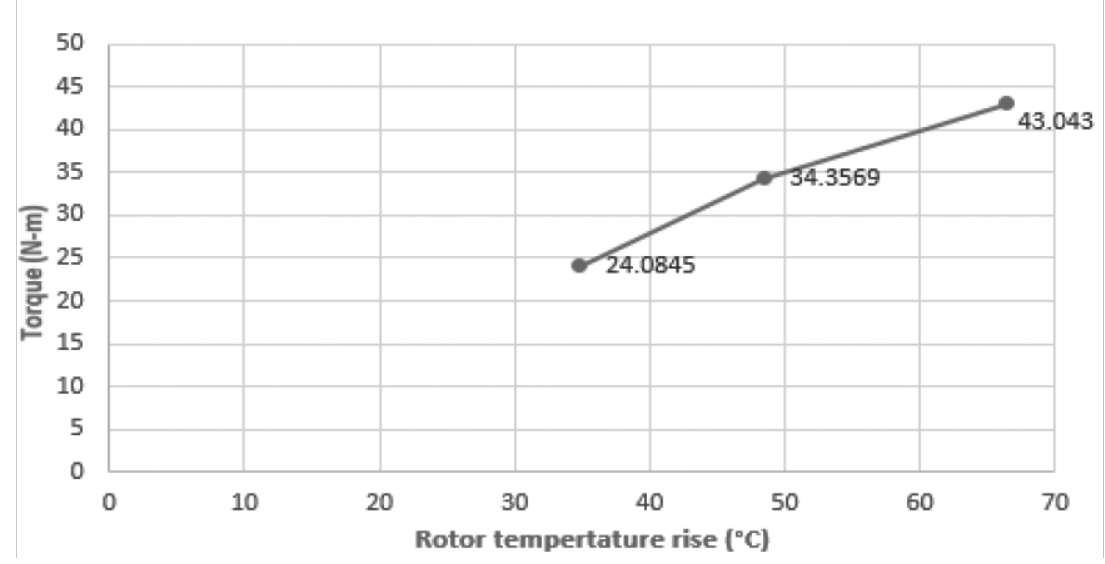

Figure 4. Temperature Vs Torque graph at different loads for $15 \mathrm{~kW} \mathrm{SCIM}$

In this work, Gaussian curve and sum of sine curve are chosen due to the closeness of plot given in Figure 5. Figure 5, indicates graphs between rotor temperature rise and torque using Gaussian curve fitting technique in MATLAB and the expression obtained in equation number (8) as follows:

$$
y=a_{1} x e^{\left[-\left(\frac{x-b_{1}}{c_{1}}\right)^{2}\right]}
$$

where $\mathrm{a} 1$ is the amplitude, $\mathrm{b} 1$ is the centroid (location), $\mathrm{c} 1$ is related to the peak width. As per minima and maxima theory first derivative of equation (9) is giving temperature as $72^{\circ} \mathrm{C}$. Using equation (1) the value full load torque is calculated as $44.3418 \mathrm{~N}-\mathrm{m}$ by substituting $15 \mathrm{~kW}$ SCIM parameters given in Appendix. Sum of Sine curve fitting technique in MATLAB and the expression obtained in equation number (9) as follows:

$y=a_{1} \times \sin \left(b_{1} \times x+c_{1}\right)$

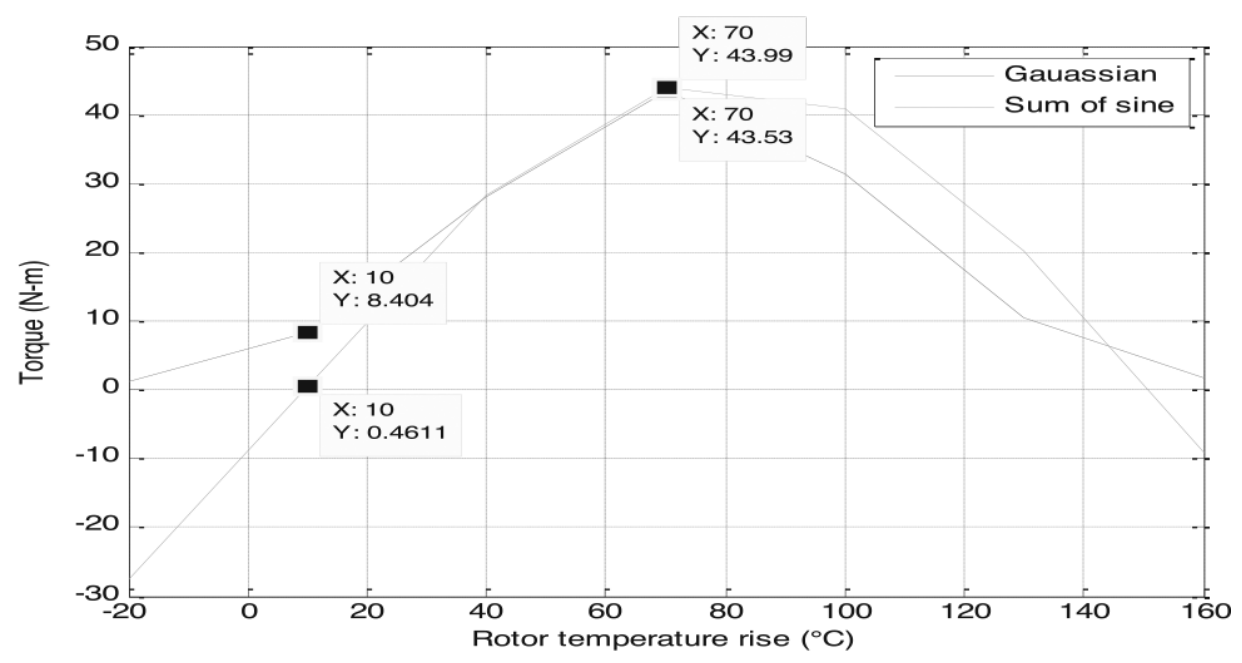

Figure 5. A $15 \mathrm{~kW}$ SCIM Gaussian curve and Sum of Sine curve 
where $\mathrm{a} 1$ and $\mathrm{b} 1$ are the row vectors for the amplitude and frequency of sine wave and $\mathrm{c} 1$ is row vector for time. From figure 5 it is observed that the temperature and full load torque is $70^{\circ} \mathrm{C}$ and $43.53 \mathrm{~N}-\mathrm{m}$ for Gaussian curve respectively. Similarly the temperature and full load torque is $70^{\circ} \mathrm{C}$ and $43.99 \mathrm{~N}-\mathrm{m}$ for sum of sine respectively. All theoretical and graphical observations are listed in Table. 4

Table 4. Comparison of rotor temperature rise and torque

\begin{tabular}{|l|l|l|l|l|}
\hline & \multicolumn{1}{|c|}{ Analytical Calculations } & \multicolumn{2}{c|}{ Graphical Observation } \\
\hline & Gaussian & Sum of Sine & Gaussian & Sum of Sine \\
\hline $\begin{array}{l}\text { Rotor } \\
\text { Temperature rise }\end{array}$ & $72^{\circ} \mathrm{C}$ & $45.14^{\circ} \mathrm{C}$ & $70{ }^{\circ} \mathrm{C}$ & $70^{\circ} \mathrm{C}$ \\
\hline Full load Torque & $\begin{array}{l}44.3418 \mathrm{~N}-\mathrm{m} \\
\text { (using eq 1) }\end{array}$ & $\begin{array}{l}44.3418 \mathrm{~N}-\mathrm{m} \\
\text { (using eq 1) }\end{array}$ & $43.53 \mathrm{~N}-\mathrm{m}$ & $43.99 \mathrm{~N}-\mathrm{m}$ \\
\hline
\end{tabular}

From Table.4 it is noted that analytical calculations of sum of sine is not matching with graphical result and analytical calculations of Gaussian is matching with graphical result. So Gaussian expression is used to analyze the performance of 11 $\mathrm{kW}$ and $18.5 \mathrm{~kW}$ SCIM. The temperature obtained from FEA of $11 \mathrm{~kW}$ and $18.5 \mathrm{~kW}$ of SCIM is in terms of resistance is substituted in equation (1) and torque is calculated. The graph between rotor temperature rise and torque are plotted for 160L frame i.e $11 \mathrm{~kW}, 15 \mathrm{~kW}$ and $18.5 \mathrm{~kW}$ as presented in Figure 6. Gaussian expression is used to analyze the performance of $11 \mathrm{~kW}$ and $18.5 \mathrm{~kW}$ SCIM. The temperature obtained from FEA is used to get the torque.

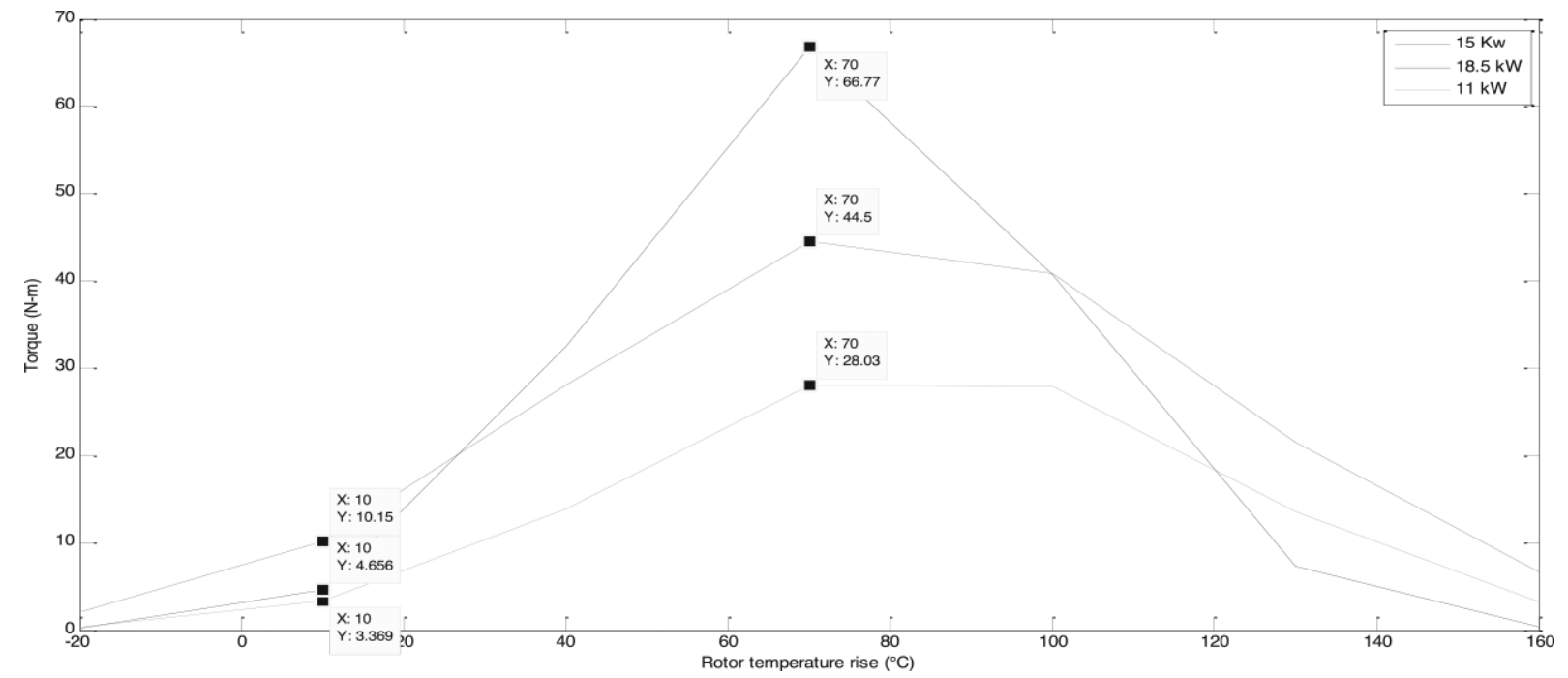

Figure 6. Graph between rotor temperature rise and torque are plotted for $160 \mathrm{~L}$ frame i.e $11 \mathrm{~kW}, 15 \mathrm{~kW}$ and $18.5 \mathrm{~kW}$ SCIM

\section{INFERENCE OF OBTAINED GENERALISED EXPRESSION}

The operation of motor depends on ambient temperature rather than temperature rise for real time scenario, so the equation (8) is modified to get the inference of ambient temperature. The productive and unproductive region of torque with respect to ambient temperature is obtained using equation (8) for $15 \mathrm{~kW}$ SCIM. Temperature rise ' $\mathrm{x}$ ' is calculated from the difference between the operating temperature of rotor at full load and ambient temperature. To determine the influence of ambient temperature on torque, ambient temperature is varied from $-25^{\circ} \mathrm{C}$ to $+50^{\circ} \mathrm{C}$ and graph is plotted between ambient temperature versus torque as shown in figure 7. From the graph it can be observed that unproductive region lies between $-5^{\circ} \mathrm{C}$ to $25^{\circ} \mathrm{C}, 25^{\circ} \mathrm{C}$ to $50^{\circ} \mathrm{C}$ and $-25^{\circ} \mathrm{C}$ to $-5^{\circ} \mathrm{C}$ are productive regions. In productive region, full load torque developed by the motor 
decreases when the ambient temperature increases from the maximum value. Since the rotor resistance depending on the ambient temperature as per equation (3), increase in ambient temperature causes reduction in full load torque in productive region. From equation (8), when ' $x$ ' is ' $b$ ' then ' $y$ ' is ' $a$ ' and which is equal to $43.62 \mathrm{~N}-\mathrm{m}$ as in Figure 7.The torque developed is depends on ambient temperature as well as temperature co efficient of material. Torque is not sufficient to drive the load in unproductive region due to equation (3).To study the impact of negative ambient temperature, full load torque is computed using equation (8) in negative region. The similar impact is observed on the negative region also.

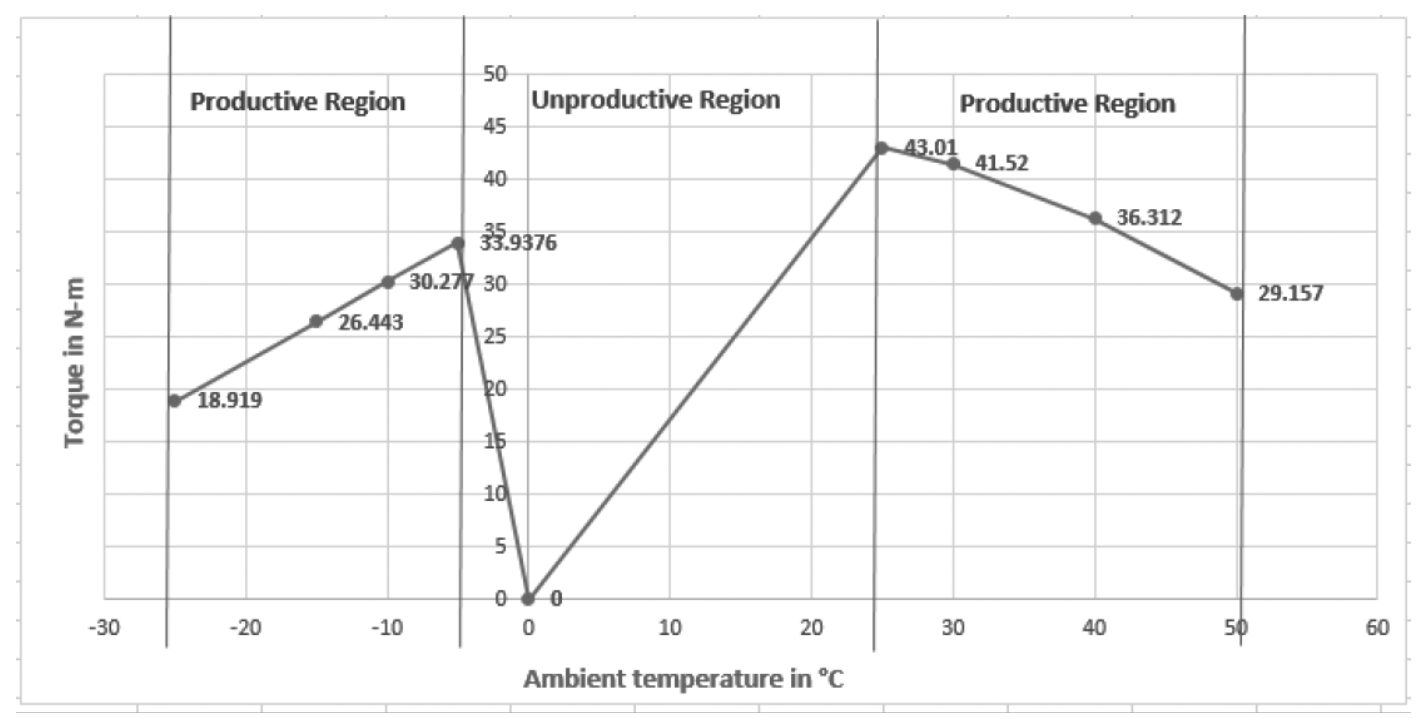

Figure 7. Graphical representation of productive and unproductive torque region with respect to ambient temperature

\section{VALIDATION OF THE RESULTS}

First derivative of the equation (9), by implication of maxima and minima theory gives

$\frac{\text { dtorque }}{\text { dtemp }}=\frac{\mathbf{d}}{\mathbf{d t e m p}}\left(\mathrm{a}_{1} \mathrm{Xe}^{\left.\left[-\left(\frac{\text { temp }-\mathrm{b}_{1}}{\mathbf{c}_{1}}\right)^{2}\right]\right)}\right)=0$

Where co-efficients of a_1 $=43.62, b \_1=72.15, c \_1=48.43$ obtained from Gaussian in curve fitting technique. The value of temperature rise obtained using equation $(11)$ is $72.15^{\circ} \mathrm{C}$. From figure 5 , the observed value of maximum temperature rise is $70^{\circ} \mathrm{C}$. The torque is computed from equation (9) is $44.3418 \mathrm{~N}-\mathrm{m}$ and from figure 5 the observed value of torque is $43.53 \mathrm{~N}-\mathrm{m}$ as mentioned in Table.4.

\section{CONCLUSION}

In this work, $15 \mathrm{~kW}$ TEFC type SCIM model is implemented using FEA. Heat source are calculated and given as input to the developed model of SCIM. The temperature obtained is substituted in the arrived mathematical expression of torque-temperature. Using MATLAB curve fitting technique Gaussian and sum of sine expressions are identified and compared. Gaussian expression is selected for plotting $160 \mathrm{~L}$ frame torque versus temperature curves. The results are validated with analytical method. The arrived Gaussian expression will give the value of torque for any given temperature. This will help to predict the torque of the motor used in industrial and electric vehicle applications. 


\section{APPENDIX}

\section{CALCULATION OF SPEED, ROTOR RESISTANCE AND ROTOR REACTANCE}

Synchronous speed N_s is given by,

$\mathrm{N}_{\mathrm{s}}=\frac{120 * \mathrm{f}}{\mathrm{p}}=1500 \mathrm{rpm}$

$\omega_{\mathrm{s}}=\frac{\left(2 * \pi * \mathrm{~N}_{\mathrm{s}}\right)}{60}$

Slip $\mathrm{S}$ is calculated by,

$$
\begin{aligned}
& \mathrm{N}=\left(1_{\mathrm{S}}\right) * \mathrm{~N}_{\mathrm{S}} \\
& \mathrm{S}_{\text {rated }}=\frac{\left(\mathrm{N}_{\mathrm{s}}-\mathrm{N}\right)}{\mathrm{N}_{\mathrm{s}}}=2.546 \% \\
& \mathrm{~S}_{\text {(no load) }}=\frac{\left(\mathrm{N}_{\mathrm{s}}-\mathrm{N}\right)}{\mathrm{N}_{\mathrm{s}}}=0.133 \%
\end{aligned}
$$

Stator $\mathrm{Cu}$ loss is given by,

Stator $\mathrm{Cu}$ loss $=3 *\left(\mathrm{I}_{1}\right)^{2 *} \mathrm{r}_{1}=654.2 \mathrm{~W}$

Rotor input power $\mathrm{P}_{2}$ is given by

$\mathrm{P}_{2}=\omega_{\mathrm{S}} * \mathrm{~T}=15,477.45 \mathrm{~W}$

Rotor $\mathrm{Al}$ loss is given by,

Rotor $\mathrm{Al}$ loss $=3 *\left(\mathrm{I}_{2}\right)^{2 *} \mathrm{r}_{2}^{\prime}=409.7 \mathrm{~W}$

Rotor resistance $\left(\mathrm{R}_{2}\right)$ is given by:

$\mathrm{R}_{2}=$ Rotor Copper losses / (3*square of rated current)

$\mathrm{R}_{2}=\frac{409.7}{3^{*}(28.18)^{2}}=0.1719 \Omega$

Where R1 is stator resistance in $\Omega$

The transformation constant $(\mathrm{K})$ is calculated as:

$\mathrm{R}_{\mathrm{k}}=\frac{\mathrm{R}_{1}+\mathrm{R}_{2}}{\mathrm{~K}^{2}}$

$0.7076=0.2746+\frac{0.1719}{\mathrm{~K}^{2}}=>\mathrm{K}=0.6301$

The rotor reactance (X2) is given by:

$\mathrm{X}_{2}{ }^{\prime}=\mathrm{X}_{1}=\frac{\mathrm{X}_{\mathrm{k}}}{2}=\frac{1.6696}{2}=0.8348 \Omega \Rightarrow \mathrm{X}_{2}^{\prime}=\frac{\mathrm{X}_{2}}{\mathrm{~K}_{2}}$ 
$\mathrm{X}_{2}=\mathrm{K}^{2 *} \mathrm{X}_{2}^{\prime}=(0.6301)^{2} * 0.8348=0.3314 \Omega$

The stator reactance $(\mathrm{X} 1)$ is given by:

$\mathrm{X}_{\mathrm{k}}=\mathrm{X}^{1}+\frac{\mathrm{X}_{2}}{\mathrm{~K}^{2}}$

$1.6696=\mathrm{X}_{1}+\frac{0.3314}{0.6301^{2}}=>X_{-} 1=0.8349 \Omega$

$I_{1}=$ stator current, $I_{2}{ }^{\prime}=$ rotor current referred to the stator, $N=$ speed in $\mathrm{rpm}, \mathrm{T}=$ torque in $\mathrm{Nm}, \mathrm{r}_{1}=$ stator resistance perphase in ohm, $\mathrm{r}_{2}{ }^{\prime}=$ rotor resistance per phase referred to stator in ohm,

\section{Calculations of $\mathrm{TF}$ with rotor temperature}

The full load torque calculation for half load and insulation temperature at full load is given by, From equation number (3),

$$
\begin{gathered}
\mathrm{R}_{2}^{\prime}=\mathrm{R}_{2}(1+\alpha \Delta \mathrm{t}) \\
\mathrm{R}_{2}^{\prime}=0.1719\left\{1+(0.004308)\left[130^{\circ}-25^{\circ}\right]\right\}=0.24965 \\
\mathrm{~T}_{\mathrm{F}}=\frac{3}{2 \pi \mathrm{N}_{\mathrm{s}}} \times \frac{\mathrm{SE}_{2}^{2} \mathrm{R}_{2}}{\mathrm{R}_{2}^{2}+\left(\mathrm{SX}_{2}^{2}\right)}=\frac{3}{2 \pi \mathrm{X} 25} \times \frac{0.02546 \mathrm{X}(15.097)^{2} \mathrm{X} 0.24965}{(0.24965)^{2}+(0.02546 \mathrm{X} 0.3314)^{2}} \\
=\frac{3}{2 \pi \mathrm{X} 25} \times \frac{144.8676}{0.062396}=44.3418 \mathrm{~N}-\mathrm{m}
\end{gathered}
$$

\section{REFERENCES}

Gao, Z. 2006. Sensor less stator winding temperature estimation for induction machines. Ph.D. dissertation, School of Electrical and Computer Engineering, Georgia Institute of Technology, Dec 2006.

Kylander, G.1995. Thermal modelling of small cage induction motors. Ph.D. dissertation, School of Electrical and Computer Engineering, Chalmers University of Technology, 1995.

Boglietti, A., Cavagnino, A., Staton, D., Shanel, M., Mueller, M. and Mejuto, C.2009. Evolution and modern approaches for thermal analysis of electrical machines. IEEE Trans. Industrial Electronics, 56(3), pp.871-882, 2009.

Bai B., Yu Q., Wang X.2010. 3-D Thermal analysis and computation of flameproof induction motor. Power and Energy Engineering Conference (APPEEC), Asia-Pacific, pp. 1-4. IEEE. (March 2010).

Jebaseeli, E.A.E., Paramasivam, S.2015. Prediction of thermal behavior of Switched Reluctance Machine using regression technique. Electrical, Computer and Communication Technologies (ICECCT), IEEE International Conference on , pp. 1-5. IEEE, March 2015.

S. Mezani., N. Takorabet., B. Laporte. 2005. A combined electromagnetic and thermal analysis of induction motors. IEEE Trans. on Magnetics, vol. 41, no. 5, pp. 1572-1575, May 2005.

D. Staton., A. Boglietti., A. Cavagnino. 2005. Solving the More Difficult Aspects of Electric Motor Thermal Analysis in Small and Medium Size Industrial Induction Motors. IEEE Trans. on Energy Conversion, vol. 20, no. 3, pp. 620-628, Sept 2005. 
A. Boglietti., A. Cavagnino.,D. A. Staton. 2005. TEFC induction motors thermal models: a parameter sensitivity analysis. IEEE Trans. on Industry Applications, vol. 41, no. 3, pp. 756-763, May-June 2005.

Yuangjiang Liu. 2000. 3D thermal stress analysis of the rotor of an induction motor. IEEE Trans. on Magnetics, vol. 36, no. 4, pp. 1394-1397,doi: 10.1109/20.877699, Jul. 2000.

Boglietti, A., Cavagnino, A., Staton.,D.A., Popescu.,M Cossar, C., McGilp, M.I. 2008. End space heat transfer coefficient determination for different induction motor enclosure types. Industry Applications Society Annual Meeting, IAS'08. IEEE, pp. 1-8. IEEE. October 2008.

Cezário, C.A., Verardi M., Borges S.S., da Silva J.C., Oliveira, A.A.M. 2005. Transient thermal analysis of an induction electric motor. 18th International Congress of Mechanical Engineering, pp. 10-11. 2005, November.

Dutta, B., Chowdhury, S.K. 2013. Steady state thermal model of TEFC induction machine. Power Electronics, Drives and Energy Systems (PEDES), IEEE International Conference on pp.1-6. IEEE. December 2013.

Gao, Z., Habetler T.G., Harley R.G., Colby R.S.2005. An adaptive Kalman filtering approach to induction machine stator winding temperature estimation based on a hybrid thermal model. Industry Applications Conference, Fourtieth IAS Annual Meeting. Conference Record of the 2005, Vol. 1, pp. 2-9. IEEE. October 2005.

Mynarek P., Kowol, M. 2011. Thermal analysis of three-phase induction motor using circuit models. Electrodynamics and Mechatronics (SCE III), 3rd International Students Conference on pp. 119-122. IEEE. October 2011.

Popova, L. 2011.Combined electromagnetic and thermal design platform for totally enclosed induction machines.978-1-4244-9303. IEEE. 2011.

Wu Y., Gao, H. 2006. Induction-motor stator and rotor winding temperature estimation using signal injection method. IEEE Trans on Industry Applications, 42(4), pp.1038-1044. 2006.

Theraja B.L. 1990. Electrical Technology, Vol-2, ninth edition, Nirja Constructions and Development, New delhi. 1990.

Omar Badran., Hussain Sarhan., Bilal Alomour. Thermal performance analysis of induction motor. IJHT Trans. 30.1_12.

Mellore.p.,Robert.D., Turner. D. 1991. Lumped parameter thermal model for electrical machines of TEFC design. IEEE Proceedings, Vol. 138, sep-1991.

Staton D., Boglietti A., Cavagnino A. 2003. Solving the More Difficult Aspects of Electric Motor Thermal Analysis. IEMDC, 1-4, Madison Wisconsin, USA. June 2003.

Weili Li., Junci Cao. 2010. Electrothermal analysis of induction motor with compound cage rotor use for PHEV. IEEE Trans. Industrial Electronics, Vol. 57, No.2, Feb. 2010.

Xypteras J., Maras K., Spyrelis. 1995. Calculation of the Temperature Distribution in an Asynchronous Machine. European Transctions on Electric Power, Vol. 5, No. 3, 6 p, May/June.1995.

Roman Pechanek V., Kindl B., Skala. 2015. Transient thermal analysis of small squirrel cage motor through coupled FEA. MM Science journal. march.2015.

TECO e-motions, 1956. Standard Motor Catalogue IE2/IE3.

CRI Motors, 2005. ISO 9001\&14001 COMPANY, IE3 Motors 